\title{
Finite element-based simulation and analysis of dragline bucket in static and dynamic loading condition
}

\author{
Shah Fateh Azam* and Piyush Rai \\ Indian Institute of Technology (BHU), Varanasi 221005 India
}

Draglines are bulky and expensive machines widely utilized in opencast mines for overburden stripping. Due to tedious working conditions, a variety of fatigue failures in dragline components are common. Bucket is one of the main components of dragline, and it is a source of external load on the machinery than its interaction through broken rock material directly. Hence, dragline buckets are the most vulnerable components of wear, tear and related failures. This article analyses the von Mises stresses using the finite element method (FEM) under the static and dynamic loading conditions. In this study, the three-dimensional solid bucket models were developed in AUTO CAD and were investigated for stress, deformation, and safety factor on the dragline bucket under static and dynamic loading conditions using the ANSYS 18 software. FEM outcomes have been highlighted from teeth, the arc of anchors and hitch elements have a maximum value of stress and a minimum value of safety factor under various loading conditions. The purpose of this study was to prognosticate the bucket failure, the strength of bucket teeth and identify the sensitive areas of the dragline bucket.

Keywords: Dragline bucket, loading conditions, static and dynamic.

DRAGLINES are used to remove the overburden (up to $50 \mathrm{~m}$ depth) and expose the minerals in a surface mine. Generally, draglines are more than 4000 tonne in mass, with bucket sizes from $24 \mathrm{~m}^{3}$ to $120 \mathrm{~m}^{3}$. The principal cost of a $62 \mathrm{~m}^{3}$ of bucket capacity of dragline is Rs 500 crore approximately. A dragline arrangement contains a big bucket which is suspended from a boom by wire ropes. The hoist rope is generally powered by big electric motors or diesel; the bucket and hoist-coupler are supported by the boom. The drag rope is used to pull the bucket assembly horizontally ${ }^{1}$. By skilful manoeuvre of the hoist and the drag ropes, the bucket is controlled for several operations. A dragline bucket schematic diagram system is shown in Figure 1. The bucket is an important part of a dragline. The capital cost of a $62 \mathrm{~m}^{3}$ bucket size

*For correspondence. (e-mail: shahfateh.azam29@gmail.com)

is around Rs 13 crore approximately. It has been observed that operational and resultant stress differences are essential issues that cause unstable stress to damage the dragline bucket and its operational life ${ }^{2}$.

This analysis includes the examination and understanding of the stress distribution and safety factor of a dragline bucket body under various loading and working conditions. For examining all the critical parameters, the numerical modelling technique was used.

\section{Static and dynamic loading conditions}

This study has been conducted under two conditions. One is static, and the other is dynamic loading conditions. In the static loading condition, only bucket payload (mass of loaded material) is considered without considering any bucket movement. The FEA model simulates the formation cutting process in sub-layers for various geometries. Velocity, displacement and resistive forces are essentially considered in dynamic loading conditions.

Finite element analysis (FEA) is always used for analysis and simulation under different loading conditions of the dragline. In the cutting process of a sub formation with several geometries to simulate with an FEA model ${ }^{2}$. Studies on the soil-blade contact, based on predefined horizontal and vertical failure surfaces to examine the nature of the soil-blade interface of three-dimensional (3D) finite element method (FEM) were carried out ${ }^{3}$. The effect of blade cutting force on the bucket width and lateral boundaries was estimated. The study also aimed to develop a numerical method and find the static equilibrium position of a predictable dragline digging system, with the static position of the bucket, and internal loading acting on an element of the excavation system ${ }^{4}$. DEM method is used for modelling of bucket filling in a complicated granular flow ${ }^{5,6}$. The components of the excavator were studied to identify the problems faced while performing the lifting and digging operation ${ }^{7}$. Further, to find the stresses at the tip of bucket teeth, the bucket was designed in such a way that the force applied on the tips of its teeth is in static loading condition ${ }^{8}$. Abacus software was used to create a $3 \mathrm{D}$ model of the dragline bucket and determine the stresses $^{2}$. The penetration 


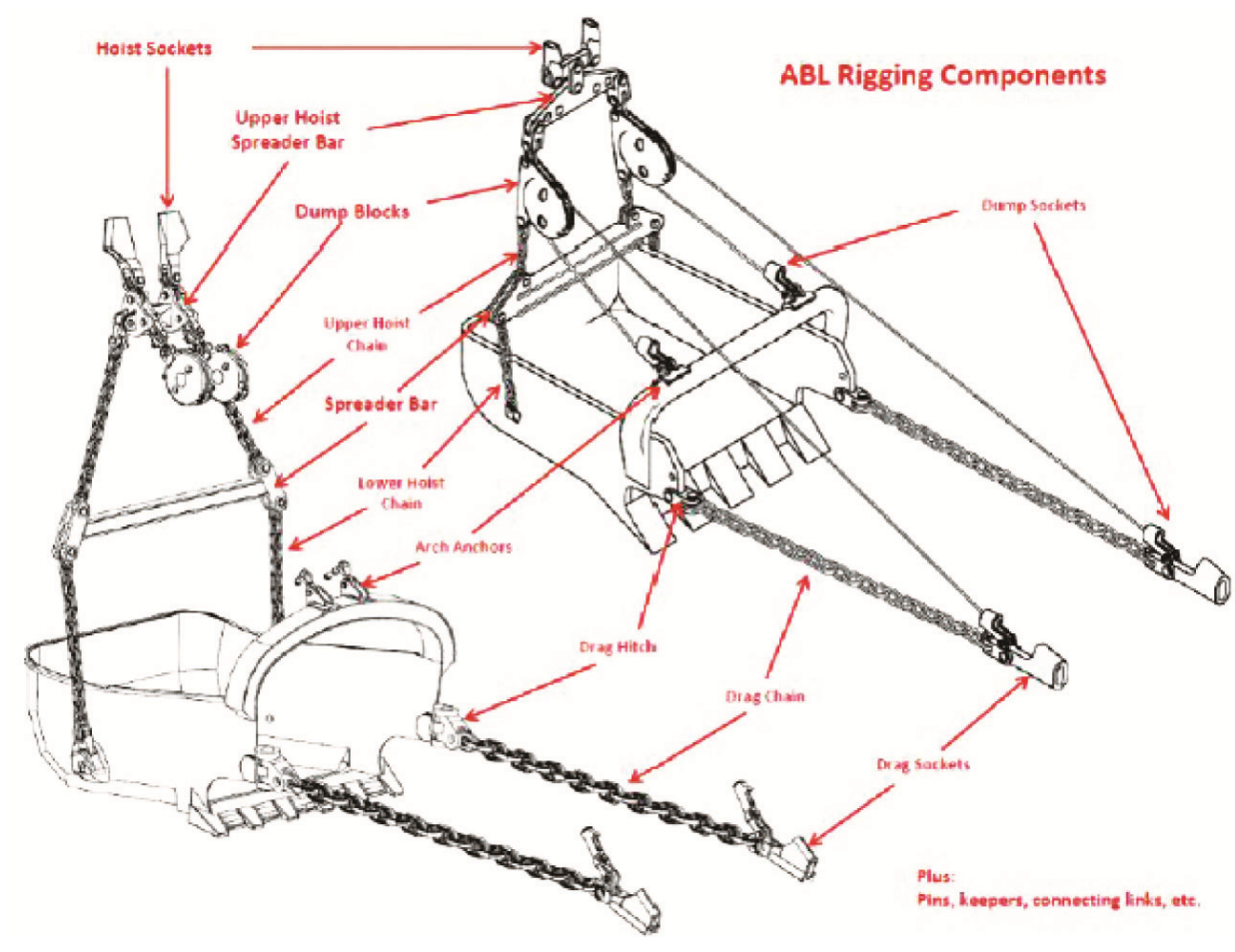

Figure 1. Schematic diagram of a bucket ${ }^{1}$.

mechanism of walking dragline buckets was studied and analysed $^{9}$.

\section{Methodology}

\section{Numerical modelling}

For calculating the strength of the structures working under known boundary and loading conditions, finite element analysis is the most significant method. The FEM analysis of any structural element helps in forecasting the structural mass and design, when subjected to stress conditions ${ }^{1}$.

FEM is an efficient numerical method ${ }^{10}$. It is used for simulation and analysis. FEMs are used in the design development and optimization of mechanical parts. The simulation results include deformation, equivalent stress, safety factor and fatigue life under different loading conditions. For estimating equivalent stress, the von Mises theory has been used. Von Mises stresses are safe and effective for design engineers. An engineer can predict the failure of machine design if the von Mises stress value induced in the material is greater than the strength of the material as shown in eq. (1). It suits well in most cases, especially in ductile materials ${ }^{1}$

$$
\left(\sigma_{1}-\sigma_{2}\right)^{2}+\left(\sigma_{2}-\sigma_{3}\right)^{2}+\left(\sigma_{3}-\sigma_{1}\right)^{2} \leq 2\left(\frac{S_{y t}}{N}\right)^{2},
$$

where $\sigma_{1}, \sigma_{2}$ and $\sigma_{3}$ are principal stresses, $S_{y t}$ the yield strength and $N$ is the safety factor.

\section{Dragline bucket geometry}

3D solid model of a dragline bucket was developed in AUTO CAD. The dragline bucket solid model generated in AUTO CAD is shown in Figure 2. This solid bucket model was imported to solid works software and converted to an IGES file, which was then imported to ANSYS 18 to simulate the dragline bucket for applying loading and boundary condition.

\section{Material property}

The bucket material was steel and the material properties of a dragline bucket are given in Table 1 .

From the 3D solid model, the volume of the bucket was $62 \mathrm{~m}^{3}$, and the mass of the empty bucket was 70 tonne. When sandstone was filled in the bucket, the total mass of the bucket increased naturally. Considering sandstone as broken rock material with a density of $2400 \mathrm{~kg} / \mathrm{m}^{3}$, the analysis was done under different loading conditions ${ }^{1}$.

\section{Analysis and simulation}

ANSYS 18 is a FEA tool used for structural analysis. It includes dynamic, linear and nonlinear studies. This 


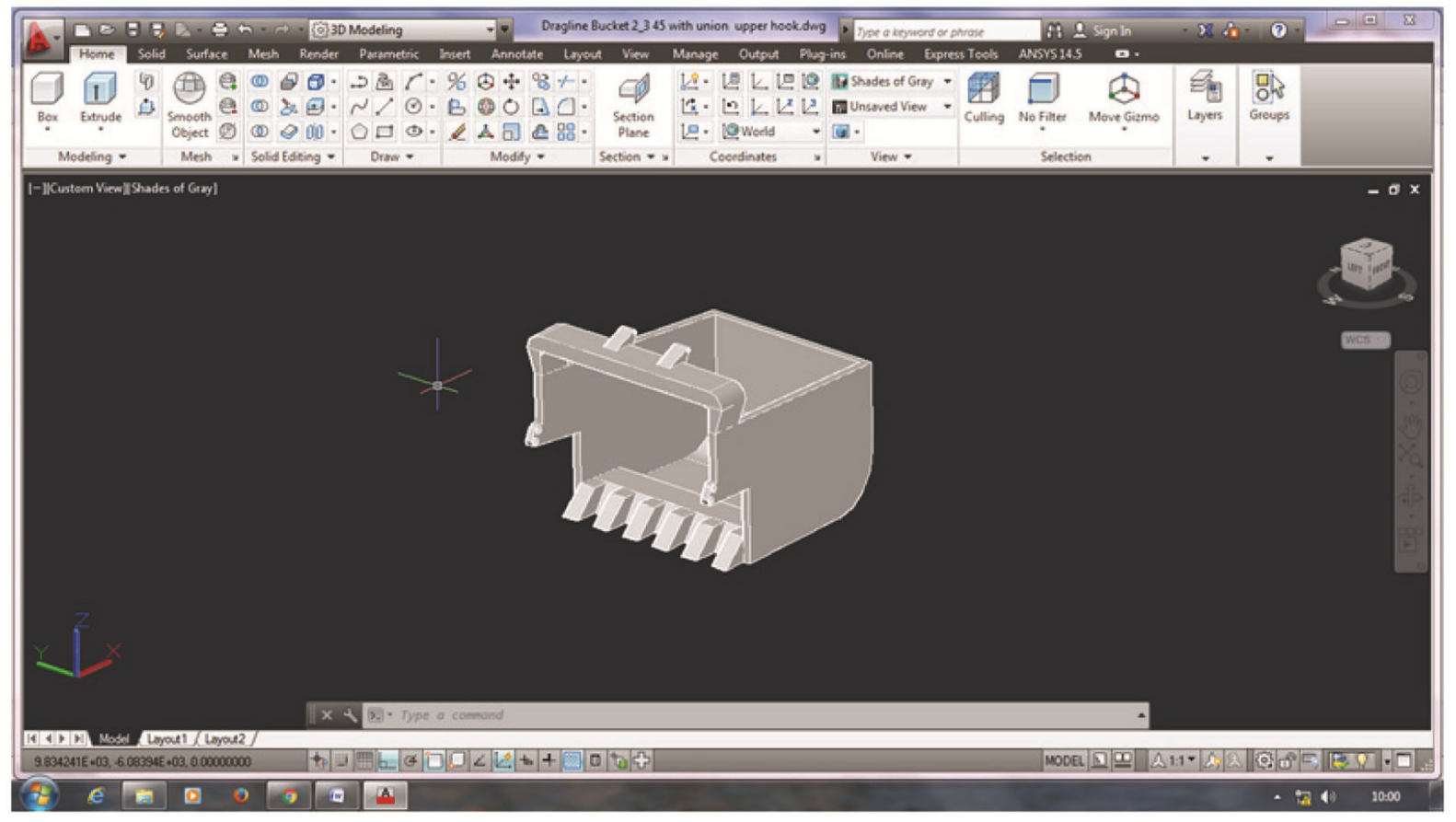

Figure 2. Three-dimensional solid bucket model.

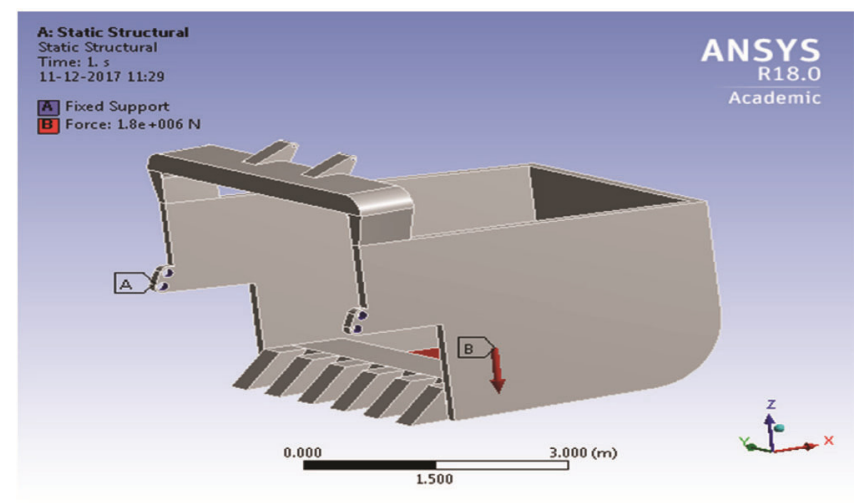

Figure 3. Boundary and loading condition of bucket model.

Table 1. Material properties of a dragline bucket

\begin{tabular}{lc}
\hline Material & Steel \\
\hline Density & $7.85 \mathrm{e}-006 \mathrm{~kg} \mathrm{~mm}^{-3}$ \\
Ultimate tensile strength & $460 \mathrm{MPa}$ \\
Yield strength (tensile) & $250 \mathrm{MPa}$ \\
Poisson's ratio & 0.3 \\
Young's modulus & $2 . \mathrm{e}+005$ \\
\hline
\end{tabular}

computer simulation method provided finite element models, behaviour and support, material models and equation solvers for a wide variety of mechanical design related problems. In this study, there were two cases, namely static and dynamic loading conditions. Static loading condition occurred in one cycle of dragline bucket with the boom moving, and the bucket still under loaded conditions. Dynamic loading condition occurred when the bucket moved in forward direction and filled the broken rock material.

Case 1 -Static loading condition: The static condition is a case in which the hitch element and the arc of anchors were fixed. In the static loading condition, the load was applied on the filled bucket in a hanging position just after loading, and immediately before the commencement of the swinging operation. Therefore, under this situation, the role of the vertical load along the base of the bucket was considered to play a critical role. This was further validated by the stress distribution at the arc of anchors and hitch elements. The boundary and loading conditions are shown in Figure 3.

The meshing of the solid bodies was carried out using the tetrahedron method and element size was taken as $50 \mathrm{~mm}$. Meshing pattern is illustrated in Figure $4 a$. The resultant meshing body incorporates 115,611 solid elements and 199,991 nodes.

When the bucket is loaded: In this loading condition the bucket is filled with sandstone. In this study, the broken sandstone with a density of $2400 \mathrm{~kg} / \mathrm{m}^{3}$ was considered for the estimation of the bucket payload.

$$
\begin{aligned}
& m=\rho \times V \\
& m=2400 \times 62 \\
& m=148,800 \mathrm{~kg} .
\end{aligned}
$$

CURRENT SCIENCE, VOL. 116, NO. 4, 25 FEBRUARY 2019 

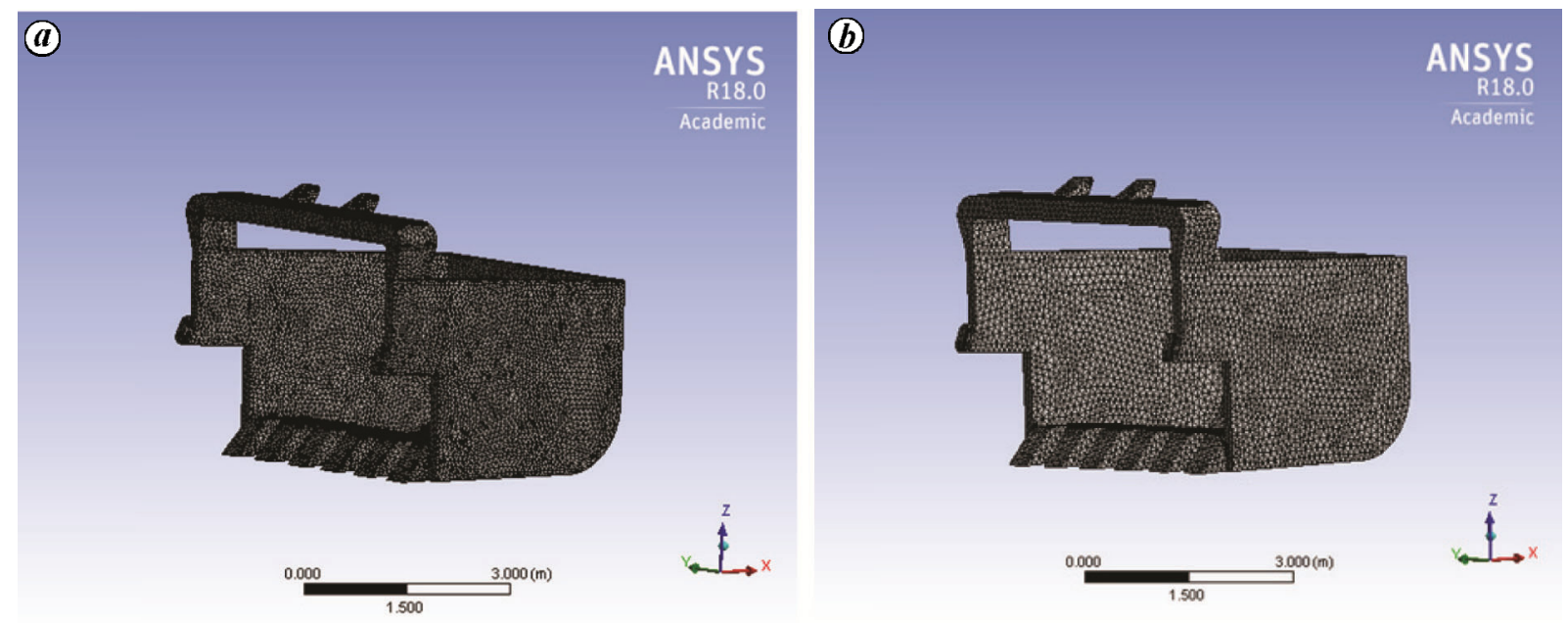

Figure $4 \boldsymbol{a}, \boldsymbol{b}$. Meshing body of bucket (50 $\mathrm{mm}$ and $100 \mathrm{~mm}$ element size).

Total mass $=$ mass of sand stone + mass of bucket

$$
\begin{aligned}
& =148,800+7000 \\
& =218,800 \mathrm{~kg}
\end{aligned}
$$

Total load $\left(F_{2}\right)=\mathrm{m} \times \mathrm{g} \times f$

$$
\begin{aligned}
& F_{2}=218,800 \times 10 \times 0.85 \\
& F_{2}=18.59800 \times 10^{5} \mathrm{~N},
\end{aligned}
$$

where $m$ is the mass in $\mathrm{kg}, \rho$ the density of sandstone $\mathrm{kg} / \mathrm{m}^{3}, V$ the bucket volume in $\mathrm{m}^{3}$ and $f$ is the fill factor of the bucket is assumed as 0.85 .

\section{Results and discussion}

The results were expressed in terms of equivalent stress, deformation and fatigue life under static and dynamic loading conditions of the dragline bucket.

Case 1 - Static loading condition: The load applied on the bucket in a static loading condition was $18.6 \times 10^{5} \mathrm{~N}$.

In this case, it was found that the self-weight plus payload applied to the dragline bucket base and the von Mises equivalent stress varied between 60.781 and $2.4826 \times 10^{8} \mathrm{~Pa}$ in the hitch element and arc of anchors of the bucket. Further, in this case, the bucket fatigue life varied from 12,026 to $1 \times \mathrm{e}^{6}$ cycle. It was also observed that the factor of safety was minimum near the hitch element and arc anchors are shown in Figure $5 a-d$.

Case 2 - Dynamic loading condition: Dynamic loading condition calculated the resultant resistive forces, since the behaviour of action-reaction evolution was important in estimating the opposite stresses in the stripping drive of the dragline bucket. There are many analytical and empirical methods available for analysing the forces during the cutting formation. In this study we used McKyes 2D model eq. (2), to calculate the forces due to cohesion, weight, inertia, overloading, and adhesion to speed up the resistance of a formation to earthmoving ${ }^{11}$

$$
T=w\left(\gamma g d 2 N_{\gamma}+c d N_{C}+C_{a} d N_{c a}+q d N_{q}+\gamma v 2 d N_{a}\right) .
$$

However, this study handles the model in terms of cutting the formation with constant velocity through a dragging movement. Finally, the 2D model of McKyes' equation is condensed to eq. (3)

$$
T=w\left(\gamma g d 2 N_{\gamma}+c d N_{c}\right)
$$

where $w$ is the width of the bucket, $\gamma$ the density of soil, $g$ the gravity, $d$ the tool depth below the soil, $c$ the soil cohesion, $N$, coefficients for weight $(\gamma)$ and cohesion $(c)$ was developed by eq. (4). The friction angle chart has been given in ref. 12, where $\varphi$ and $\delta$ are the internal and external friction angles ${ }^{2}$

$$
N_{X}=N_{0}+\left(N_{\varphi}-N_{0}\right) \frac{\delta}{\varphi} \text {. }
$$

The parameters which are used in eqs (3) and (4) are obtained from a tillage research study ${ }^{13}$. The calculated weight coefficient, cohesion coefficient and resultant cutting force are given in Table 2. The resistive force against the cutting force was estimated at $222.94 \mathrm{kN}$ approximately.

\section{Finite element mesh and boundary conditions}

In this study, FEA modelling and simulation studies were carried out on ANSYS 18. The material specification corresponds to steel with a strength of $460 \mathrm{MPa}$, showing 

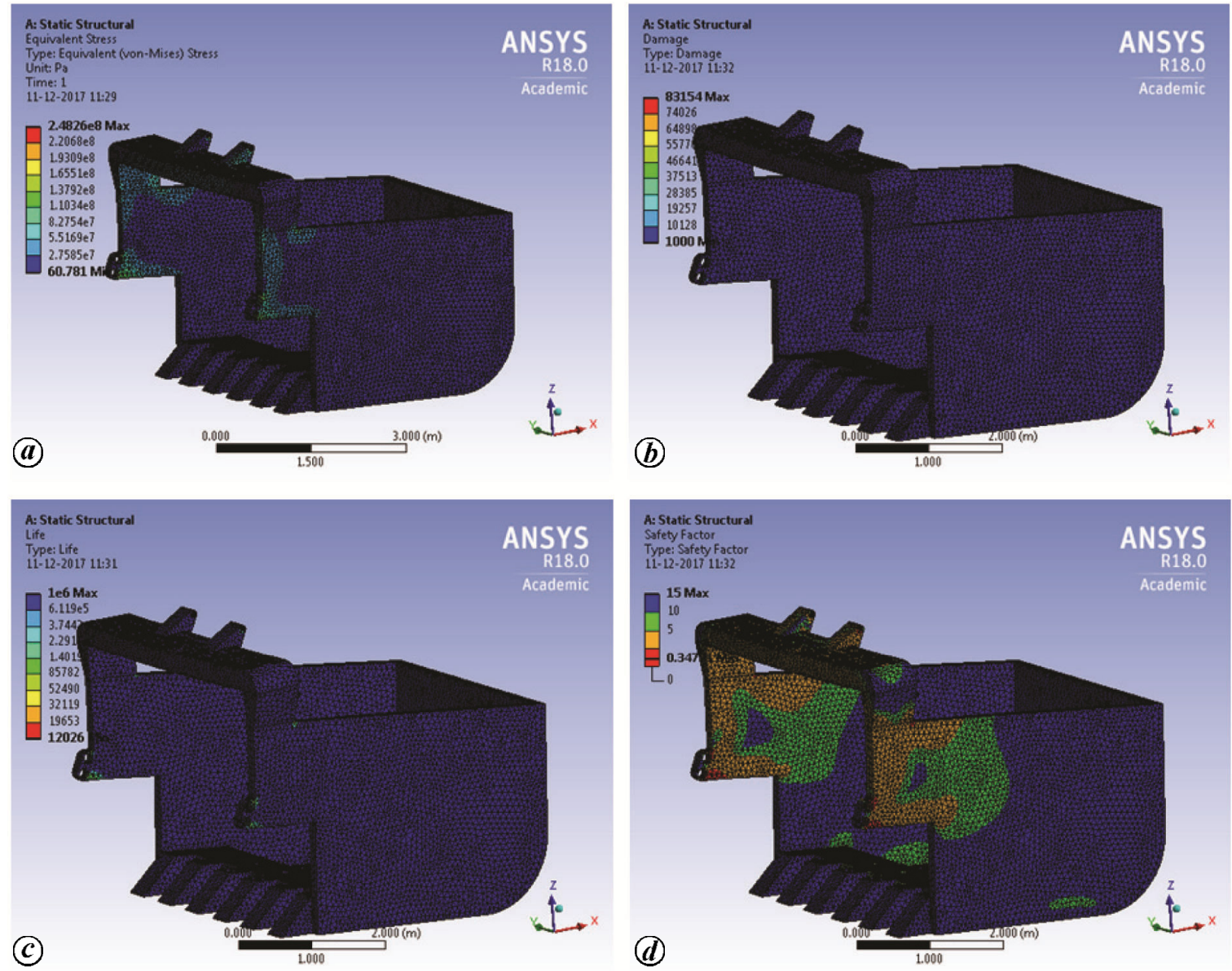

Figure $5 \boldsymbol{a}-\boldsymbol{d}$. Results of analysis in bucket loaded condition. $\boldsymbol{a}$, Equivalent stress (von-Mises); $\boldsymbol{b}$, Damage; $\boldsymbol{c}$, Life; $\boldsymbol{d}$, Safety factor.

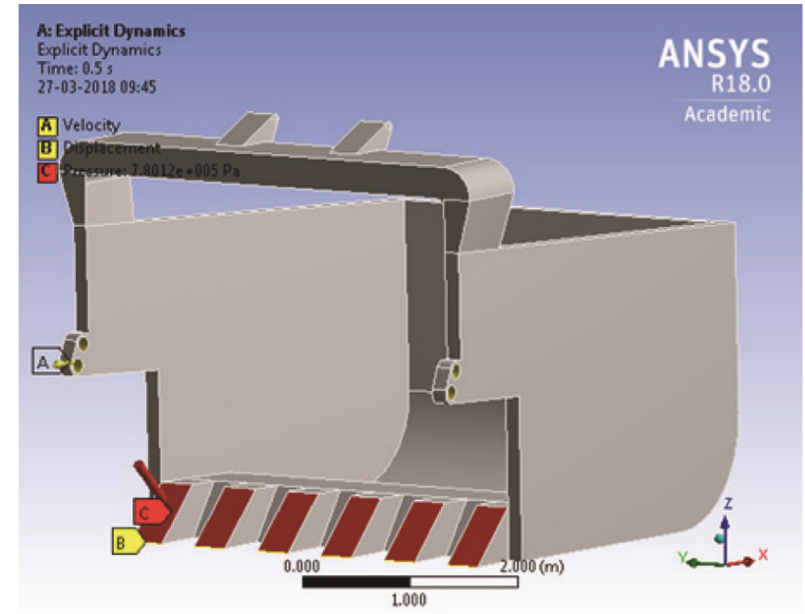

Figure 6. Boundary condition of moving bucket.

elastic-perfectly plastic behaviour. The meshing of solid bodies was carried out using a four-node linear tetrahedron continuum element. The meshing of the solid bodies was carried out using the tetrahedron method and element size was taken as $100 \mathrm{~mm}$. Meshing pattern is illustrated
Table 2. Input parameters

\begin{tabular}{lc}
\hline Parameter & Value \\
\hline Formation cohesion strength $(c, \mathrm{kPa})$ & $25 \mathrm{KPA}$ \\
Density of formation $(\gamma)$ & $2.40 \mathrm{t} / \mathrm{m}^{3}$ \\
Internal friction angle $(\varphi)$ & $40^{\circ}$ \\
External friction angle $(\delta)$ & $30^{\circ}$ \\
Weight coefficient $(\mathrm{N} \gamma)$ & 2.375 \\
Cohesion coefficient $(\mathrm{Nc})$ & 3.4 \\
Resultant cutting force $(\mathrm{T})$ & $222.94 \mathrm{KN}$ \\
\hline
\end{tabular}

in Figure $4 b$. The resultant meshing body incorporates 75,542 solid elements and 18,315 nodes. The loading and boundary conditions of the moving bucket model are shown in Figure 6.

Teeth using its weight, proceeds to cut the formation using the dragging force conveyed along the drag rope during the entire filling cycle. The cutting action of the bucket controls the bucket filling cycle and leads to stripping of the formation at a velocity between 0.50 and $1.5 \mathrm{~m} / \mathrm{s}$. Simulation in this study uses external pressure applied to the bucket teeth, and the bucket velocity is $0.50-1.5 \mathrm{~m} / \mathrm{s}$ in the $x$-direction. 
RESEARCH ARTICLES
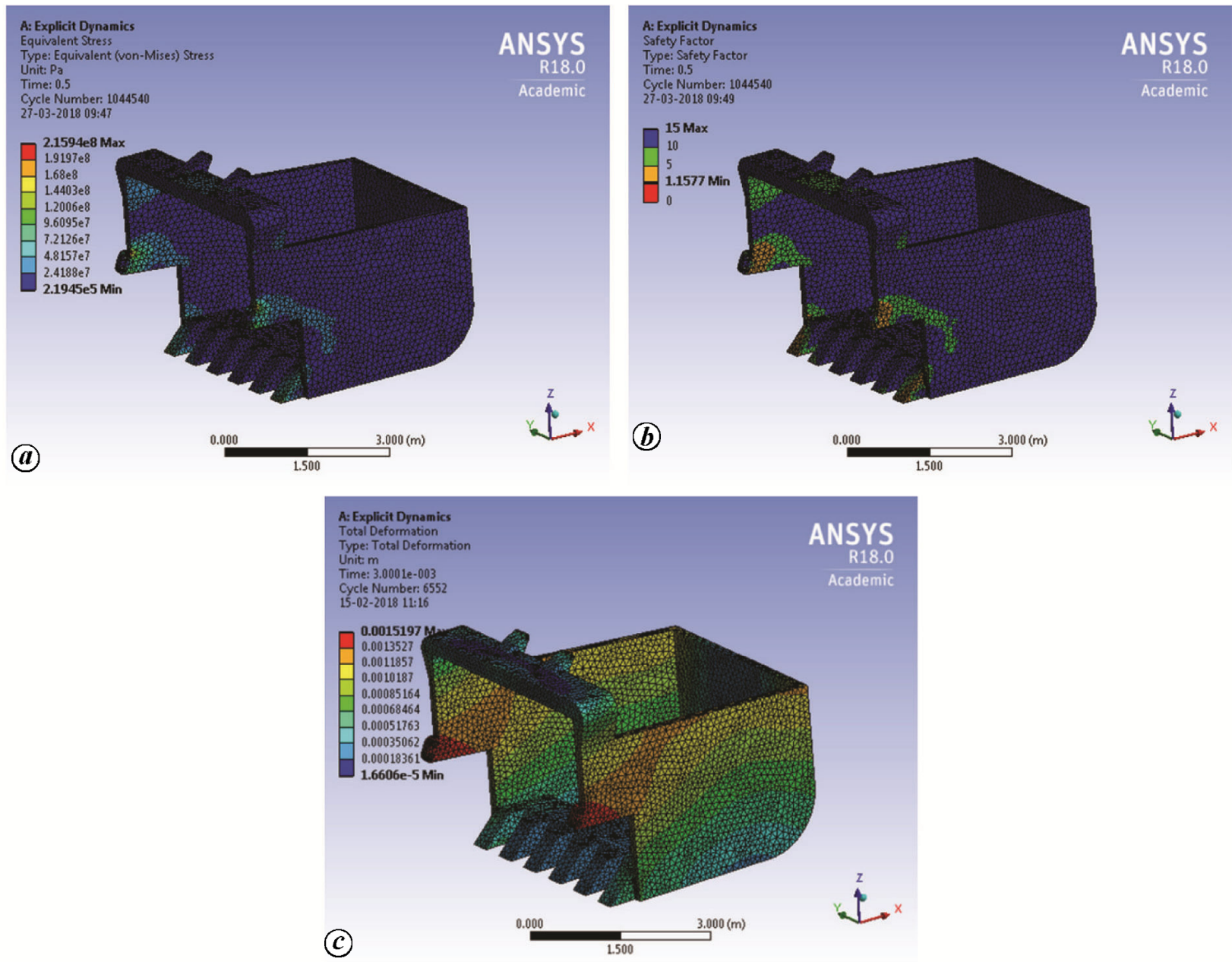

Figure $7 \boldsymbol{a}-\boldsymbol{c}$. Results of analysis in bucket moving condition. $\boldsymbol{a}$, Von-Mises stress variation; $\boldsymbol{b}$, Safety factor; $\boldsymbol{c}$, Deformation of bucket teeth and hitch elements.

Table 3. Comparison between static and dynamic loading conditions

\begin{tabular}{lll}
\hline S1. No. & \multicolumn{1}{c}{ Static loading condition } & \multicolumn{1}{c}{ Dynamic loading condition } \\
\hline Stress distribution field & $\begin{array}{l}\text { Stress distribution field covers the arc of anchors, } \\
\text { hitch element and side plates of the } \\
\text { bucket (Figure } 5 \mathrm{a} \text { ) }\end{array}$ & $\begin{array}{c}\text { Stress distribution field covers the teeth, hitch element } \\
\text { and side plates of the bucket (Figure } 7 \mathrm{a} \text { ) }\end{array}$ \\
& $\begin{array}{l}\text { The arc of anchor and hitch element } \\
60.78-248.26 \times 10^{6} \mathrm{~Pa}\end{array}$ & $\begin{array}{l}\text { Teeth and hitch element } \\
2.19 \times 10^{5}-216.4 \times 10^{6} \mathrm{~Pa}\end{array}$ \\
\hline $\begin{array}{l}\text { Stress concentration point } \\
\text { Values of stress }\end{array}$ &
\end{tabular}

\section{von Mises stress on the dragline bucket}

The established 3D model simulates the formation cutting action of the dragline bucket. Stress accumulated in the teeth and hitch element of the moving bucket initiates the failure of the configuration in the teeth area. Simulation results show the maximum stress zones that have maximum probability to failure in this location. The von Mises stress distribution for the moving conditions of the bucket is shown in Figure $7 a$. It was found that the von
Mises stress varied from $2.19 \times 10^{5}$ to $2.16 \times 10^{8} \mathrm{~Pa}$. To increase the service life of the bucket and several other elements, it is recommended that a higher grade or alloyed steel be used in the sensitive parts of the bucket.

From the analysis, it has been observed that the safety factor is minimum near the hitch element and teeth tip as evident in Figure $7 b$. The deformation of teeth and hitch element is evident in Figure $7 c$. The comparison of stress distribution under static and dynamic loading conditions is given in Table 3. 

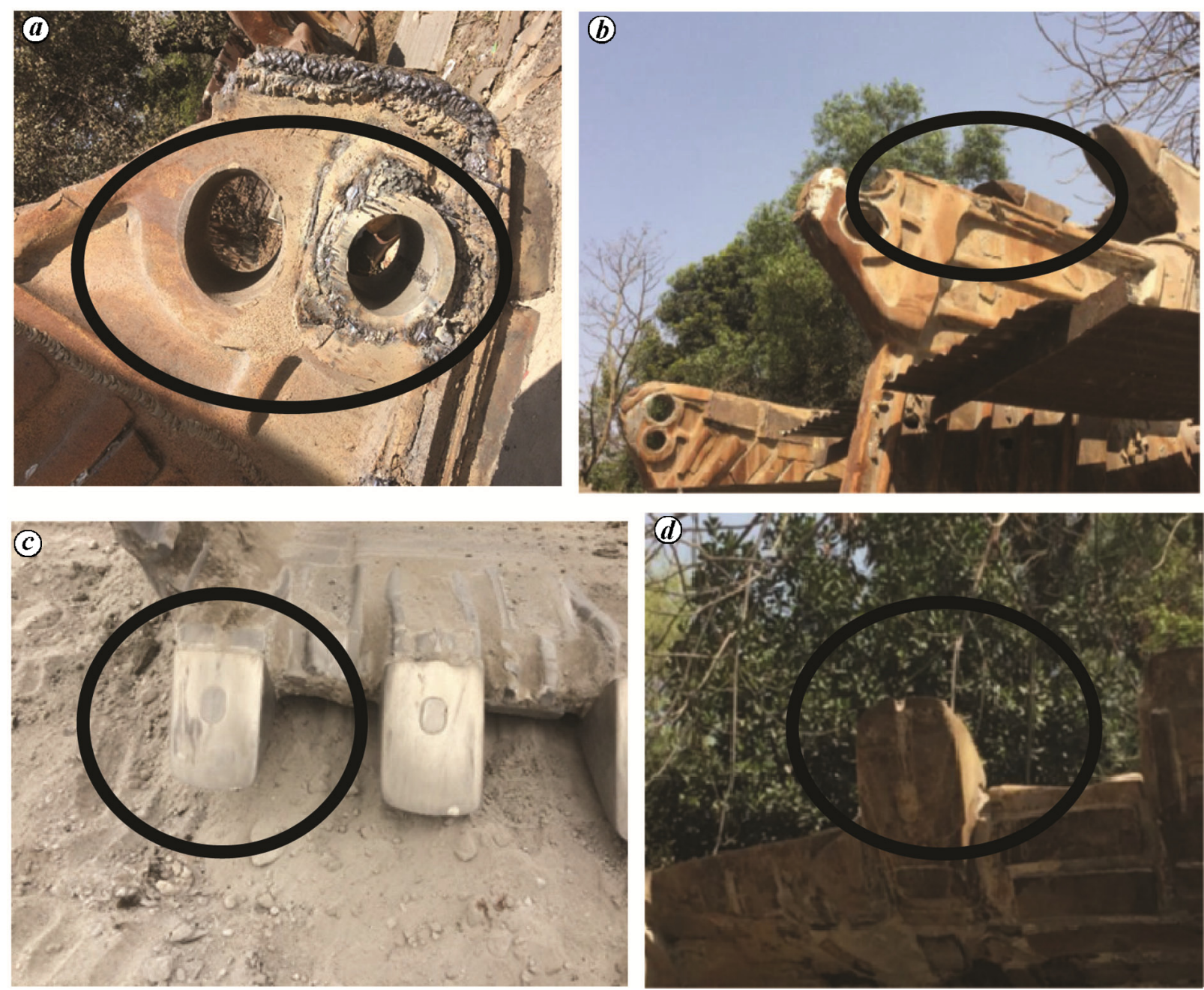

Figure $8 \boldsymbol{a}-\boldsymbol{d}$. Deformation and damage of hitch element and bucket teeth.

\section{Validation}

The dragline worked almost 20-21 h per day. Some small maintenance was required during shift change-overs. Generally, shift maintenance was done in the morning. While validating the results of the simulation study, it was found from the official maintenance logs that the shortest working life was that of the bucket teeth. It varied from 200 to $300 \mathrm{~h}$ in the given sandstone formation. The entire bucket is replaced after approximately $3-$ 4 years of its operation in the field. The stress generated shaped deformation, and damage to the hitch element was observed in the study mine as shown in Figure $8 a, b$. Similarly, the damaged teeth of the dragline bucket are shown in Figure $8 c, d$.

It was found from the simulation results that stress is accumulated in the hitch element and bucket teeth. Figure $8 a-d$ shows the deformation and damage of hitch elements from different dragline buckets in the mine. Figure $8 d$ shows that a small part of the teeth tip was broken and Figure $8 c$ shows that the teeth were worn out and de- formed under dynamic conditions. The maintenance logs of the study mine also reported maximum failure at the tip of teeth and the hitch element of the bucket.

\section{Conclusion}

(1) Under the static loading condition, the maximum von Mises stress value was located near the arc of anchors and hitch element. Hence the probability of failure at these locations. (2) Under dynamic loading condition, the maximum von Mises stress value was located near the teeth of the bucket and near the hitch element. Hence the probability of failure at these locations. (3) The safety factor is minimum at the tip of the teeth and hitch element of the bucket. (4) The simulation outcomes showed maximum von Mises stress values on the dragline bucket teeth and hitch elements. Hence the probability of failure at this location. (5) In this analysis, the maximum von Mises stress on the moving bucket condition was $216 \mathrm{MPa}$ at the given loading and boundary condition 
situations. Though this maximum stress may not cause failure of the whole body of the bucket, any overfilling condition may induce fatigue or fractures at critical locations in the bucket.

1. Azam, S. F. and Rai, P., Modelling of dragline bucket for determination of stress. ASME J., 2018, 78, 392-402.

2. Golbasi, O. and Demirel, N., Investigation of stress in an earthmover bucket using finite element analysis: A generic model for draglines. J. S. Afr. Inst. Min. Metall., 2015, 115(7), 623-628.

3. Abo-Elnor, M., Hamilton, R. and Boyle, J. T., Simulation of soilblade interaction for sandy soil using advanced 3D finite element analysis. Soil Till. Res., 2004, 75(1), 61-73.

4. Costello, M. and Kyle, J., A method for calculating static conditions of a dragline excavation system using dynamic simulation. Math. Comput. Model., 2004, 40(3-4).

5. Coetzee, C. J. and Els, D. N. J., The numerical modelling of excavator bucket filling using DEM. J. Terramechanics, 2009, 46(5), 217-227.

6. Coetzee, C. J., Els, D. N. J. and Dymond, G. F., Discrete element parameter calibration and the modelling of dragline bucket filling. J. Terramechanics, 2010, 47(1), 33-44.

7. Bende, S. B. and Awate, N. P., Design, modeling and analysis of excavator arm. Int. J. Design Manuf. Technol., 2013, 4, 14-20.
8. Tupkar, M. P. and Zaveri, S. R., Design and analysis of an excavator bucket. Int. J. Sci. Res. Eng. Technol., 2015, 4(3), 227229.

9. Ozdogan, M. and Machinery, I., Walking dragline bucket penetration mechanism and penetration forces, 2015; https://doi.org/ 10.13140/RG.2.1.2304.8406.

10. Abo-Elnor, M., Hamilton, R. and Boyle, J. T., 3D Dynamic analysis of soil-tool interaction using the finite element method. $J$. Terramechanics, 2003, 40(1), 51-62.

11. McKyes, E. (ed.), Soil Cutting and Tillage, Elsevier, Amsterdam, 1985 , p. 7.

12. Hettiaratchi, D. R. P. and Reece, A. R., The calculation of passive soil resistance. Geotechnique, 1974, 24(3), 289-310.

13. Mouazen, A. M. and Neményi, M., Finite element analysis of subsoiler cutting in non-homogeneous sandy loam soil. Soil Till. Res., 1999, 51(1-2), 1-15.

ACKNOWLEDGEMENT. We are indebted to the management and staff of Northern Coal Field, Singrauli for their excellent co-operation and support during the entire field work.

Received 9 August 2018; revised accepted 6 November 2018

doi: $10.18520 / \mathrm{cs} / \mathrm{v} 116 / 14 / 612-619$ 